\title{
Vascularized Bone Grafts for the Treatment of Scaphoid Nonunion
}

\author{
Tomas A Esteves and Jorge G Boretto* \\ Hand and Upper Extremity Department, Prof. Carlos Ottolenghi "Italian Hospital of Buenos Aires, Argentina
}

Submission: December 19, 2017; Published: January 19, 2018

*Corresponding author: Jorge G. Boretto, Hand and Upper Extremity Department, Institute of Orthopedics and Traumatology, Potosí 4247 , C1199ACK, Autonomous City of Buenos Aires, Argentina, South America, Email: jorge.boretto@hospitalitaliano.org.ar

\begin{abstract}
Scaphoid nonunion without treatment can progress to carpal collapse and a predictable pattern of radiocarpal arthrosis. Surgical intervention is indicated to prevent progressive carpal instability and arthritis. In proximal pole nonunion and occasionally in scaphoid waist fracture with osteonecrosis, or when traditional bone grafting has failed to achieve union, vascularized bone grafts are used because they improve the biology of bone healing. This review describes the most common vascularized bone grafts used to treat scaphoid nonunion, either pedicled or free.
\end{abstract}

\section{Introduction}

Scaphoid fractures are the most common carpal fracture and continue to present diagnostic and therapeutic challenges. Delayed diagnosis, inadequate initial management, proximal fracture location, osteonecrosis (ON), and associated carpal instability with acute scaphoid fracture can lead to nonunion of the scaphoid waist or the proximal pole [1]. Left untreated, scaphoid nonunion can progress to carpal collapse and a predictable pattern of radiocarpal arthrosis [2]. Surgical intervention is indicated to prevent progressive carpal instability and arthritis if fracture union is not achieved by 6 months after initial surgery. Open reduction and internal fixation in combination with non-vascularized bone graft (NVBG) is indicated as the main procedure [3]. However, in proximal pole non-unions and occasionally in scaphoid waist fractures with osteonecrosis, or when traditional bone grafting has failed to achieve union, vascularized bone grafts (VBG) are used. Although the use of VBG is more technically challenging than that of NVBG, VBG improves the biology of healing, maximizes the odds of achieving union, and may help revascularize a necrotic proximal pole [4].

VGB for the treatment of scaphoid nonunion can be divided in those that are harvested in the vicinity (local flaps), and are rotated on a pedicle and those harvested in another anatomical region from the wrist (distant flaps). These last ones require microsurgical transfer. Here, we describe the most common VBG used to treat scaphoid nonunion and their results.

Pedicle VBG

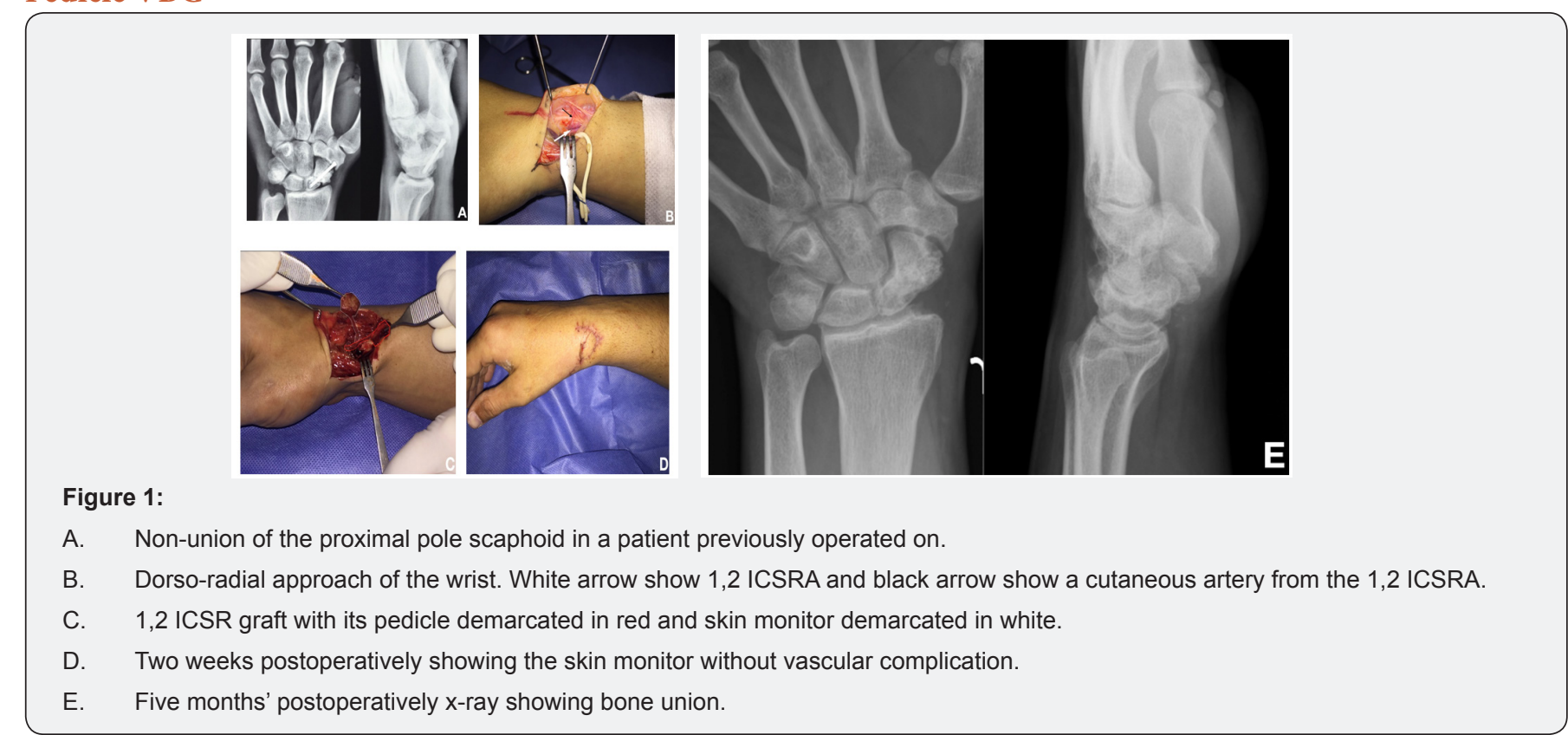


Local grafts from the dorsal or volar distal radius are the most common used in the setting of scaphoid nonunion. The dorsal bone graft is based on either the 1,2 or 2,3 intra-compartmental supraretinacular artery (ICSRA) (Figure 1). The volar bone graft is based on the volar carpal artery. The first authors who described 1,2 ICSRA grafts were Zaidemberg et al. [5]. They treated 11 patients with scaphoid nonunion and achieved complete union and average length of immobilization to radiographic and clinical union in 6.2 weeks, improving range of motion and grip strength of the wrist after surgery. Later, Tu et al. [6] reported, on a series of 72 patients with scaphoid nonunion treated with VBG, a union rate of $90.28 \%$ and satisfactory function rate of $81.94 \%$ in acute scaphoid fractures with an average follow-up of 5 years. The dorsal vascularized distal radius graft was based on either the 1,2 ICSRA or 2,3 ICSRA, with the latter able to provide a longer pedicle to reach the scaphoid with less tension.

In 1987 Kuhlmann et al. [7], after a cadaveric dissection of 79 wrist, reported three cases using a VBG based on the volar carpal artery. Spontaneous pain regressed completely and the patients present greatly improved motion. Gras \& Mathoulin [8] reported on 73 cases as a primary procedure achieving $96 \%$ of union rates and 38 cases with persistent scaphoid nonunion following previous surgical management, the authors reported a union rate of $89.5 \%$, with an average time to union of 10.8 weeks. They conclude that this VBG seems feasible as a primary intervention.
Dorsal grafts may be better suited for management of scaphoid nonunion that involve the proximal pole and those without significant humpback deformity because adequate correction of the deformity often requires a separate volar approach and increased soft-tissue dissection. The 2,3 ICSRA provides a longer pedicle and allows for a greater arc of graft rotation than the 1,2 ICSRA. Relative contraindications to pedicled dorsal radius vascularized bone grafting include humpback deformity, carpal instability, or collapse. Volar-based grafts may be more useful when deformity correction is needed, but these grafts may be limited by a short pedicle [3].

\section{Free VBG}

The free VBGs from the iliac crest or the medial femoral condyle are an option of treatment when pedicled graft are contraindicated or when a structural support is needed to correct carpal instability due to scaphoid shortening. Free vascularized medial femoral condyle (MFC) grafts provide blood supply and greater structural support, which improves deformity correction [9] (Figure 2). Doi et al. [10] developed this vascularized small bone graft harvested from the condylar region of the femur based on the articular branch of the descending genicular artery and vein and contains periosteum with cortical-cancellous bone. They used this free graft also for other bone nonunion associated to fractures with promising results either as a cortical-cancellous or cortical-periosteum graft.

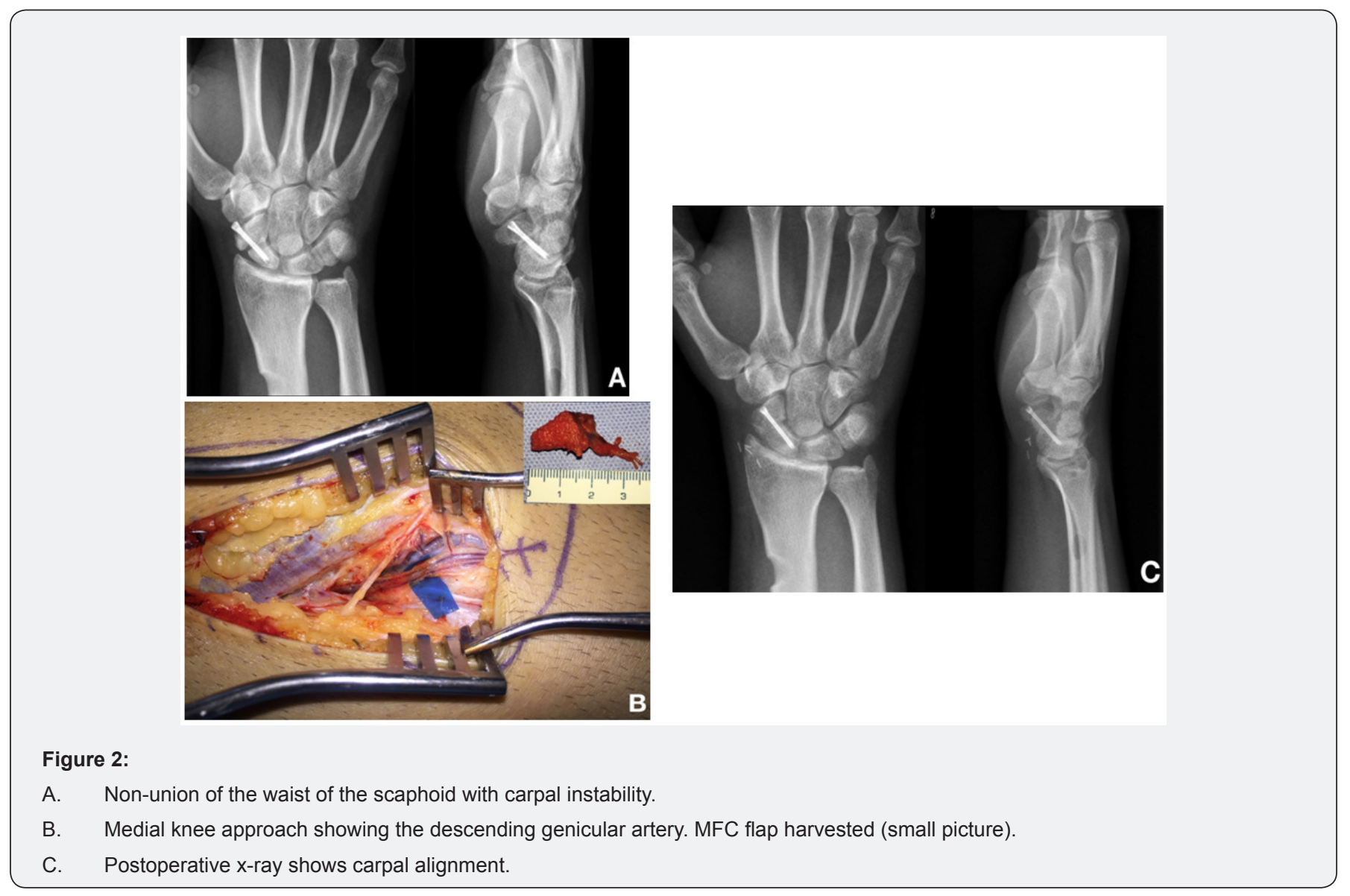


Burger et al. [11] described a series of 16 patients with scaphoid reconstruction with medial femoral trochlea (MFT) osteochondral flaps. In the early follow-up, the computed tomography scans confirmed healing in 15 of 16 reconstructed scaphoids. The patient who failed to achieve union was a smoker and continued to have wrist pain, although it was somewhat diminished. She subsequently had additional surgery with placement of a revision screw and bone graft. All patients experienced at least some improvement in wrist pain and range of motion similar to preoperative. The MFT graft provides both a robust and consistent vascular supply and optimal density of mostly cancellous bone from which large grafts can be harvested and shaped to fit the scaphoid defect with minimal donor site morbidity, and should be considered in the unique setting of a scaphoid nonunion with proximal pole $\mathrm{ON}$ and carpal collapse [12].

Wong et al. [13] propose a lateral femoral condyle flap as an alternative source of vascularized bone from the distal femur. They work on thirty-one fresh cadaveric limbs and concluded this flap could be an option for reconstruction of osseous defects of the upper extremity due to the anatomy of this flap enables designs combining soft tissue, bone, and cartilage. Another option is the use of a free vascularized iliac crest bone graft. Arora et al. [14] evaluated this VBGs and internal fixation with Kirschner wires to treat patients who had recalcitrant scaphoid nonunions with evidence of $\mathrm{ON}$ after at least two previous failed operations. In the 16 patients who achieved union, wrist extension, radial deviation of the wrist, and grip strength increased after surgery but was accompanied by a reduction in active flexion and ulnar deviation. The range of wrist movement will not return to the pre-injury level. Prevention of progressive carpal collapse, the absence of donor site morbidity, good subjective results and pain relief, justifies this procedure in the treatment of recalcitrant nonunion of the scaphoid [14].

\section{Conclusion}

Treatment of scaphoid non-union can be challenging. When the scaphoid has adequate perfusion and the grafts are rigidly fixed NVBG techniques can achieve high rates of union. In the presence of $\mathrm{ON}$ or proximal nonunion, VBG improves the chance of union but are more technically demanding than NVBG. Selection of a vascular pedicle is dependent of the surgeon's familiarity with techniques. Local grafts from the dorsal or volar distal radius allow for rotation of a pedicle without the need for microvascular anastomoses but in presence of humpback deformity, carpal instability, or collapse the free VBGs are a good option. Although some free VBG have been described, the MFC flap has many advantages and is a significant option for this pathology.

\section{Conflict of Interest}

The authors have nothing to declare.

\section{References}

1. Waitayawinyu T, McCallister WV, Nemechek NM, Trumble TE (2007) Scaphoid nonunion. J Am Acad Orthop Surg 15(5): 308-320.

2. Ruby LK, Stinson J, Belsky MR (1985) The natural history of scaphoid non-union. A review of fifty-five cases. J Bone Joint Surg Am 67(3): 428-432.

3. Moon ES, Dy CJ, Derman P, Vance MC, Carlson MG (2013) Management of nonunion following surgical management of scaphoid fractures: current concepts. J Am Acad Orthop Surg 21(9): 548-557.

4. Sunagawa T, Bishop AT, Muramatsu K (2000) Role of conventional and vascularized bone grafts in scaphoid nonunion with avascular necrosis: A canine experimental study. J Hand Surg Am 25(5): 849-859.

5. Zaidemberg C, Siebert JW, Angrigiani C (1991) A new vascularized bone graft for scaphoid nonunion. J Hand Surg Am 16(3): 474-478.

6. Tu YK, Chen AC, Chou YC, Ueng SW, Ma CH, et al. (2008) Treatment for scaphoid fracture and nonunion--the application of $3.0 \mathrm{~mm}$ cannulated screws and pedicle vascularised bone grafts. Injury 39(4): 96-106.

7. Kuhlmann JN, Mimoun M, Boabighi A, Baux S (1987) Vascularized bone graft pedicled on the volar carpal artery for non-union of the scaphoid. J Hand Surg Br 12(2): 203-210.

8. Gras M, Mathoulin C (2011) Vascularized bone graft pedicled on the volar carpal artery from the volar distal radius as primary procedure for scaphoid non-union. Orthop Traumatol Surg Res 97(8): 800-806.

9. Sawaizumi T, Nanno M, Nanbu A, Ito H (2004) Vascularised bone graft from the base of the second metacarpal for refractory nonunion of the scaphoid. J Bone Joint Surg Br 86(7): 1007-1012.

10. Doi K, Hattori Y (2009) Vascularized bone graft from the supracondylar region of the femur. Microsurgery 29(5): 379-384.

11. Burger HK, Windhofer C, Gaggl AJ, Higgins JP (2013) Vascularized medial femoral trochlea osteocartilaginous flap reconstruction of proximal pole scaphoid nonunions. J Hand Surg Am 38(4): 690-700.

12. Kakar S, Bishop AT, Shin AY (2011) Role of vascularized bone grafts in the treatment of scaphoid nonunions associated with proximal pole avascular necrosis and carpal collapse. J Hand Surg Am 36(4): 722-725.

13. Wong VW, Burger HK, Iorio ML, Higgins JP (2015) Lateral Femoral Condyle Flap: An Alternative Source of Vascularized Bone From the Distal Femur. J Hand Surg Am 40(10): 1972-1980.

14. Arora R, Lutz M, Zimmermann R, Krappinger D, Niederwanger C, et al. (2010) Free vascularised iliac bone graft for recalcitrant avascular nonunion of the scaphoid. J Bone Joint Surg Br 92(2): 224-229. 
This work is licensed under Creative Commons Attribution 4.0 License

DOI: 10.19080/OROAJ.2018.10.555780

\section{Your next submission with Juniper Publishers} will reach you the below assets

- Quality Editorial service

- Swift Peer Review

- Reprints availability

- E-prints Service

- Manuscript Podcast for convenient understanding

- Global attainment for your research

- Manuscript accessibility in different formats ( Pdf, E-pub, Full Text, Audio)

- Unceasing customer service

Track the below URL for one-step submission https://juniperpublishers.com/online-submission.php 